\title{
DIFFERENT MODALITIES OF USING FACEBOOK: THE INFLUENCE OF ACTUAL SOCIAL RELATIONS, WELLBEING, AND ATTITUDE TOWARDS THE MEDIUM
}

\author{
Stefano TARTAGLIA \\ Department of Psychology, University of Turin \\ Via Verdi 10, 10124, Turin, Italy \\ E-mail: stefano.tartaglia@unito.it
}

\begin{abstract}
The online social networks attract the social scientists' attention because of their large diffusion and their social and psychological impact. The majority of the studies focus on Facebook because it is the largest one. There are contrasting opinions on the positivity of that social medium. It is not possible to reach univocal results considering the use of Facebook as a whole. It is better to distinguish different modalities of use. This study investigates these modalities and predicts them on a sample of young adults in Italy. The analyses were carried out in two steps. The first one identifying the modalities of using Facebook and the attitudes towards it. The second one testing the influence of different predictors: actual social relations, wellbeing, and the attitudes towards the medium. Participants use Facebook in different ways. Implications are discussed.
\end{abstract}

Key words: self-esteem, satisfaction with life, social relations, social media, Facebook

In the last twenty years internet has changed the human life in several aspects, different internet tools (email, forums, blogs ...) allowed new forms of social interaction and communication among people. At the beginning of the century the evolution of the internet-based applications allowed a new way of using the web. The internet became a platform where the contents are published and continuously modified by the users in a participatory fashion. This new way of creating and exchanging user-generated content on the internet was called Web 2.0 and the Social Media are the internet applications that allow it (Kaplan \& Haenlein, 2010). Among the social media one of the most used subcategory are the online social networks (e.g., MySpace, Facebook). These sites attracted the social scientists' attention because of their large diffusion and their social and psychological impact. Searching in the PsychINFO database (on 28 May 2014) we found 177 publications containing the word 'MySpace' in the abstract, 506 containing 'Twitter', and 1249 containing the word 'Facebook'. Of course, the specific medium is not irrelevant because every social networking site has particular features. Nevertheless, there are similarities and the majority of the studies focused on Facebook (FB) because it is the largest one with over 1 billion active users in 2013 .

New technologies and social media are used particularly by young people (Holzner, 2009) but from the beginning of the Web 2.0 the situation is changing with the spread of this service to larger groups of users. Concerning FB in 2010, the fastest growing group of users was the one in the age group of over 34 years (Wilson, Gosling, \& Graham,

DOI: $10.21909 /$ sp.2016.01.703 
2012). There are contrasting opinions on the positivity of social media. Some stress the new opportunities they offer, others consider them as just another aspect of the so-called liquid modernity (Bauman, 2000). Anyway, the fact is that at present they are a social phenomenon involving a great part of the population of the rich countries. For instance, in Italy in $2013,44.3 \%$ of the entire population had a FB profile (Censis, UCSI, 2013).

\section{The Social Networking Sites and the Actual Social Relations}

The creators of the social networking sites define them as social utilities helping people tocommunicate with their friends and acquaintances. According to Wilson and colleagues (2012),19\% of studies on FB examined the motivation of using it. The main motivations identified are the desire to keep in touch with friends (Bosch, 2009; Ellison, Steinfield, \& Lampe, 2007; Lewis \& West, 2009; Pempek, Yermolayeva, \& Calvert, 2009; Sheldon, 2008) and tomeet new people(Ellison, Steinfield, \& Lampe, 2007; Sheldon, 2008; Urista, Dong, \& Day, 2009; Zhao, Grasmuck, \& Martin, 2008). The first one is justified by the opportunity the medium offers to manage off-line social networks and by the social pressure to use the medium becausemany other people doit. The second mayberelated to the need of minimizing loneliness. Among social scientists there are two different positions concerning the effects of social networking sites on social interactions (Kujath, 2011). One position is that virtual relations are a surrogate for face-to-face interactions and they are deteriorating relationship quality. Weak mediated ties are substituting for strong direct ties. The other opinion is that social media could be a useful tool to maintain and expand upon direct social net- works. Some authors even affirmed that FB may be a source of social capital (Ellison, Steinfield, \& Lampe, 2007). The expansion of social network should lower the feeling ofloneliness but research showed that the relation between FB use and loneliness is not univocal and depends on the specific activity that users participate in on the social networking site (Burke, Marlow, \& Lento, 2010; Wise, Alhabash, \& Park, 2010). People with different feelings of loneliness seem to use FB in different way, not more or less.

\section{Facebook and Wellbeing}

Several studies found positive relations between wellbeing and FB use (Ellison, Steinfield, \& Lampe, 2007; Gangadharbatla, 2008; Valenzuela, Park, \& Kee, 2009) suggesting that social networking sites are not an escape for people not satisfied with their life. Someone maintained also a potential positive effect of large networks on life satisfaction (Manago, Taylor, \& Greenfield, 2012). Anyway, concerning self-esteem, one of the most investigated variable, the results are not univocal. In some cases, the relation between self-esteem and FB's use is negative (Mehdizadeh, 2010) and is moderated by selfconsciousness (Lee, Moore, Park, \& Park, 2012). According to the social compensatory hypothesis the users low in self-esteem use FB more actively as a way to compensate for the deficiency in self-esteem. Other studies did not find any relation between self-esteem and FB use (Skues, Williams, \& Wise, 2012). Many scholars maintain the possibility that the use of online applications may become addictive defining the concept of Social networking addiction (Griffiths, 2013). This addiction is the failure to regulate usage of social networking sites, which leads to nega- 
tive personal outcomes (LaRose, Kim, \&Peng, 2010). Because of the large diffusion of FB, the addiction to this social networking site has been studied to a great extent (Ryan, Chester, Reece, \& Xenos, 2014). The FB addiction may affect negatively the wellbeing and, in turn, the excessive use of the site could be motivated by escaping from negative moods. In general, the relation between FB use and wellbeing is not clear.

\section{Attitude towards Facebook}

A different way to investigate the psychological predictors of FB use is to study the attitudes and expectations that people have about the medium. The so-called media choice theories (Stephens \& Sætre, 2004) maintain that individuals choose the best medium for a given communicative context on the ground of technological and social expectation about the medium. As in the case of other media, the attitudes toward online communication may influence the way people use the online social media like FB. Ledbetter (2009) identified five dimensions of the attitude towards online communication but in a subsequent study, Ledbetter and colleagues (2011) used just two of these dimensions. They found that people with a positive expectation that social networking sites help maintaining connections within a social network are more likely to communicate via FB. Contrary to their assumption, the same authors found that online self-disclosure (another positive attitude towards social medium) did not influence FB communication with friends. Using different indicators, Prescott (2014) studied the relation among attitudes and FB use in a specific context: the student-staff relation at a University in United Kingdom. The educational uses of
FB are poor but university students' general attitude towards it is positive (Hew, 2011). In general, positive attitude towards the medium should predict the use but this assumption is not always verified.

\section{Current Study}

Keeping in touch with friends and minimizing loneliness and negative mood are the main motivations of using FB. Therefore, we expect that the actual social relations and the wellbeing level of an individual influence FB use. We want to investigate the effects of these variables adding a third kind of predictor, the attitude towards FB that the media choice theories suggested may be relevant too. Moreover, we want to distinguish among various kinds of use of the medium.

We have seen that there is not a clear relation between FB use, actual social network, and wellbeing. Some authors suggest that the social networking sites may be related to a good quality of life helping to manage social relations and increasing social capital (Ellison, Steinfield, \& Lampe, 2007) but the literature is not consistent. On these grounds, we may affirm that it is not possible to try and express a general positive or negative judgement on FB use. The social media are technological artefacts used by millions of users in different ways; it is not possible to reach univocal results considering FB use as a whole. We think it would be better to distinguish different modalities of use. At present FB is a widespread social phenomenon so it is not interesting to investigate whether people use it but what they do with it. The different modalities of use may be influenced by the various expectancies that people have towards the medium, which cannot be conceptualized as a simple positive 
or negative attitude (Ledbetter et al., 2011). Ledbetter investigated specifically the attitudes towards online communication but used a different number of attitudes in different studies (Ledbetter, 2009; Ledbetter et al., 2011). Other scholars used different measures (Prescott, 2014). Finally, FB is widespread worldwide and social science research has been carried out in several different countries (Li, 2014; Prescott, 2014; Sagioglou \& Greitemeyer, 2014). Although FB is a global phenomenon, we may not assume that different cultures imply the same uses of the same medium, so it is necessary to replicate the studies in various countries.

On these grounds, the present study aims to investigate the influence of different predictors on FB use, differentiating among various possible modalities of FB use. The analysis was carried out in two steps. The first one is explorative identifying the main modalities of use of the medium and the main attitudes towards it. The second one is testing the influence of different predictors on the modalities of FB use: the actual social relations, wellbeing indexes, and the attitudes towards the medium. We expected that:

a) Actual social relations influence the use of FB in two ways; a high number of face-toface friends increase the use for managing social network (Sheldon, 2008), whereas poor relations increase the use in order to meet new people (Ellison, Steinfield, \& Lampe, 2007; Sheldon, 2008; Urista, Dong, \& Day, 2009; Zhao, Grasmuck, \& Martin, 2008).

b) High wellbeing indexes (self-esteem and satisfaction with life) increase the use of FB for managing relations and for social grooming (Ellison, Steinfield, \& Lampe, 2007; Gangadharbatla, 2008; Valenzuela, Park, \& Kee, 2009), whereas low indexes increase the compensatory use of FB as a way to com- pensate for the deficiency in self-esteem and expand social network. We chose satisfaction with life (Diener, Emmons, Larsen, \& Griffin, 1985), because it is commonly used as a general indicator of wellbeing and Selfesteem, since the previous not univocal results need to be clarified.

c) Different expectations lead to different modalities of use; the attitudes towards FB influence in different ways the modalities of use (Stephens \& Sætre, 2004).

\section{Method}

\section{Participants}

Participants were 376 university students, users ofFB(49.7\% Male; 50.3\% Female). Their average age was 23.45 years $(S D=2.38$; age range 19-30). Participants were recruited among undergraduate and graduate students ofArts and Science Schools in Italy. For their master's degree thesis, two graduate students in Psychology contacted other students attending courses of Arts and Sciences schools of two universities. The participantswere contacted in the classrooms asking for voluntary participation. The participants did not receive any incentive to respond. The majority of the students accepted. Although this sampling technique has thelimitation that it is not purely random, every effort was made to recruit students from all the different courses of the two universities. The ethnic composition of the samplewas completely homogeneous: all participants were Italians. Participants spend about three hours a day on the Internet $(M=$ 2.87 hours; $S D=2.20$ ). They connect to their FB profile almost every day (on average 5.99 days a week; $S D=1.53$ ) and they have been FB users from an average of 3.84 years $(S D=$ 1.53). 


\section{Measures}

Data were collected via self-reported questionnaire, which took about 20 minutes to complete. Anonymity of the respondents was guaranteed. Participants rated items and answered questions about different topics. The indicators used in our analysis are:

1. Modality of using Facebook. A set of 19 FB activities (e.g., "Publish Photos"; "Click the 'like' button for other people's statuses, walls, or links") was presented to participants asking "How often do you do the following things on Facebook?" Items were rated on a 4-point Likert-type scale ranging from 1 (never) to 4 (very often). These activities were selected in previous studies from a list of activities built by means of interviews of FB users ${ }^{1}$.

2. Attitude towards Facebook. A set of 14 items presenting different opinions about FB (e.g., "On Facebook, you can show something about yourself that you cannot show in the real world"; "Facebook friends are not real

\footnotetext{
${ }^{1}$ For their degree thesis, three undergraduates in Psychology interviewed other students $(N=30)$ creating a list of FB's activities and a list of opinions about FB. Then we asked a sample of High school students $(N=209)$ and a sample of University students $(N=400)$ to evaluate the two lists of items by means of a questionnaire. The analyses of the responses allowed for selecting the items of the Modalities of using FB scale and Attitudes towards FB scale used in this study. The analysis of the data collected among High school students has been presented at the 8th national congress "La prevenzione nella scuola e nella comunità" [Prevention in the school and in the community], June 23-25, 2011, Padua, Italy. The analysis of the data collected among University students has been presented in the 5 th Conference on Emerging Adulthood. October 27-28, 2011, Providence, USA.
}

friends"). Participants were asked to indicate their agreement or disagreement with each statement on a 4-point Likert-type scale ranging from 1 (strongly disagree) to 4 (strongly agree). These opinions were selected in previous studies from a list of opinions built by means of interviews of FB users ${ }^{1}$.

3. The Italian version of the Rosenberg Self-esteem scale (Prezza, Trombaccia, \& Armento, 1997) including 10 items rated on a 4-point Likert-type scale ranging from 1 (strongly disagree) to 4 (strongly agree). 5 items assessing low self-esteem were reversed before calculating the scale score. The scale showed a good internal coherence (Cronbach's $\alpha=$.78).

4. The Satisfaction with Life Scale (Diener, Emmons, Larsen, \& Griffin, 1985) including 5 items rated on a 7-point Likert-type scale ranging from 1 (strongly disagree) to 7 (strongly agree). The scale showed a good internal coherence (Cronbach's $\alpha=.87$ ).

5. Actual face-to-face relations: one item asking the number of friends usually frequented and one item asking if the person was involved in a romantic relationship.

6. A brief list of socio-demographic items (i.e., gender, age).

\section{Data Analysis}

Beside descriptive statistics, we conducted two exploratory factor analyses. The first one involved the set of items about FB's activities identifying different modalities of using FB. The second one involved the set of items presenting opinions on FB to identify different attitudes towards it. Subsequently, we performed three Hierarchical Regression Analyses to test the influence of the different groups of predictors on the modalities of using FB. 


\section{Results}

\section{Modality of Using Facebook}

We performed an explorative factor analysis (maximum likelihood extraction) on the items concerning FB's activities (Bartlett's test $=2164.75, p<.01 ; \mathrm{KMO}=.83)$. The examination of the factors' scree-plot suggested a three factors structure so we proceeded using a varimax rotation on the first three factors extracted (Eigenvalues $=5.31$; $2.25 ; 1.60)$. Overall, the factors explained a good proportion of variance (48\%) and the factor structure after the rotation (see Table 1) was easily interpretable.

11 items load on the first factor, they regard the interaction with friends (i.e., commenting on others actions) and self-expression (i.e., posting photos, videos, profile info...). We named the first factor Social Interaction. The second is loaded by 5 items about worrying, hiding, and presenting oneself. We called this Simulation because all the items are centering around presenting yourself a certain way (hiding some things, and presenting a carefully crafted "image" rather than the "real" you). The third factor is loaded by 3 items about friend requests and chatting with people you do not know. We called this Search for Relations.

\section{Attitude towards Facebook}

Also on the set of items about the attitude towards FB we performed an explorative factor analysis (maximum likelihood; varimax rotation; Bartlett's test $=848.73, p<.01$; $\mathrm{KMO}=.76$ ). The explorative factor analysis suggested a four factors structure explaining the $54 \%$ of the total variance (Eigenval- ues $=3.27 ; 1.85 ; 1.33 ; 1.10)$. Table 2 reports factor loadings above .30 .

The first two factors express two different worries about FB. The first one was named Worry about Self Image because it is loaded by items expressing an opinion that is important tomanage positivelythe self-image on FB. The second factor was named Worry about Privacy because it expresses the concern about privacy violations. The third factor depicts a positive attitude towards FB seen as useful for social relations so we called it $R e$ source for Social Relations. Unlike these, the last factor is a clearly negative attitude towards FB and we called it Dangerous Place.

\section{Hierarchical Regression Analyses}

We performed three multiple regression analyses in which the factor scores of the modalities of use of FB were regressed onto different groups of predictors. In all the models, the predictors were entered in the analyses in three steps. In the first step, we entered socio-demographic characteristics and the indicators of actual social relations: gender $(0=$ male; $1=$ female $)$, age, thenumber offriends and romantic relationship status $(0=$ single; $1=$ engaged). In the second step, we entered psychological indicators of wellbeing: Selfesteem and Satisfaction with life. In the last step, we entered the four attitudes towards FB. Overall, the average score ofSelf-esteem was $3.11(S D=.44)$ and the average score of Satisfaction with lifewas4.51 $(S D=1.25)$.

The Social Interaction use of FB (see Table 3) was positively influenced by being female, the number of friends, self-esteem, Worry about self-image, and Resource for social relations attitude. The negative attitude Dangerous place had an inverse effect on Social interaction use of FB. 
Table 1 Explorative factor analysis of the Modality of use of Facebook: Factor loadings and correlations among factors

\begin{tabular}{|c|c|c|c|}
\hline & $\begin{array}{c}\text { Social } \\
\text { Interaction }\end{array}$ & Simulation & $\begin{array}{l}\text { Search for } \\
\text { Relations }\end{array}$ \\
\hline $\begin{array}{l}\text { Comment on other people's statuses, walls, } \\
\text { or links }\end{array}$ & .88 & & \\
\hline Comment on photos & .82 & & \\
\hline $\begin{array}{l}\text { Click the "like" button for other people's } \\
\text { statuses, walls, or links }\end{array}$ & .65 & & \\
\hline Write what you are thinking on your wall & .55 & & \\
\hline Update your profile information & .55 & & \\
\hline Publish photos & .51 & & \\
\hline Chat with your friends & .43 & & \\
\hline Publish music videos & .41 & & \\
\hline Publish videos made by you and your friends & .38 & & \\
\hline Send private messages & .37 & & \\
\hline Join Facebook groups & .36 & & \\
\hline $\begin{array}{l}\text { Hide some things about yourself that you } \\
\text { don't like }\end{array}$ & & .81 & \\
\hline $\begin{array}{l}\text { Worry about what others might say about } \\
\text { you after seeing what you publish }\end{array}$ & & .61 & \\
\hline $\begin{array}{l}\text { Present yourself as something different from } \\
\text { how you appear in real life }\end{array}$ & & .56 & \\
\hline $\begin{array}{l}\text { Hide some truths about yourself from people } \\
\text { you chat with }\end{array}$ & & .54 & \\
\hline $\begin{array}{l}\text { Worry about choosing the photos you post } \\
\text { because you don't want other people to think } \\
\text { badly of you }\end{array}$ & & .52 & \\
\hline $\begin{array}{l}\text { Accepts friend request from people you don't } \\
\text { know at all }\end{array}$ & & & .86 \\
\hline $\begin{array}{l}\text { Accept friend requests from people you don't } \\
\text { know, but who are friends of friends of yours }\end{array}$ & & & .73 \\
\hline Chat with people you don't know & & & .52 \\
\hline \multicolumn{4}{|l|}{ Note. Loadings below .30 are omitted. } \\
\hline Correlations among factors & 1 & 2 & 3 \\
\hline \multicolumn{4}{|l|}{1 Social interaction } \\
\hline 2 Simulation & .03 & & \\
\hline 3 Search for relation & .04 & .06 & \\
\hline
\end{tabular}


Table 2 Explorative factor analysis of the Attitude towards Facebook: Factor loadings and correlations among factors

\begin{tabular}{|c|c|c|c|c|}
\hline & $\begin{array}{l}\text { Worry about } \\
\text { Self-Image }\end{array}$ & $\begin{array}{l}\text { Worry about } \\
\text { Privacy }\end{array}$ & $\begin{array}{l}\text { Resource for } \\
\text { Social } \\
\text { Relations }\end{array}$ & $\begin{array}{l}\text { Dangerous } \\
\text { Place }\end{array}$ \\
\hline $\begin{array}{l}\text { It is important to update your profile } \\
\text { to give a good impression to others }\end{array}$ & .70 & & & \\
\hline $\begin{array}{l}\text { It is important to appear attractive on } \\
\text { Facebook }\end{array}$ & .69 & & & \\
\hline $\begin{array}{l}\text { On Facebook it is important to hide } \\
\text { something about yourself that others } \\
\text { don't care about }\end{array}$ & .63 & & & \\
\hline $\begin{array}{l}\text { It is important to have more that } 1000 \\
\text { Facebook friends }\end{array}$ & .61 & & & \\
\hline $\begin{array}{l}\text { It is important to accept friend } \\
\text { requests only from people you know }\end{array}$ & & .78 & & \\
\hline $\begin{array}{l}\text { It is important to make your profile } \\
\text { inaccessible to people who are not } \\
\text { your friends }\end{array}$ & & .58 & & \\
\hline $\begin{array}{l}\text { It is dangerous to accept friend } \\
\text { requests from people you don't know }\end{array}$ & & .45 & & \\
\hline $\begin{array}{l}\text { It is not dangerous to give personal } \\
\text { information (e.g., phone number) to } \\
\text { people you don't know that make } \\
\text { friend requests on Facebook }\end{array}$ & & -.31 & & \\
\hline $\begin{array}{l}\text { Some friendships begin on Facebook } \\
\text { and then continue in other contexts }\end{array}$ & & & .60 & \\
\hline $\begin{array}{l}\text { It is easier to meet people on } \\
\text { Facebook than in reality }\end{array}$ & & & .47 & \\
\hline $\begin{array}{l}\text { On Facebook, you can show } \\
\text { something about yourself that you } \\
\text { cannot show in the real world }\end{array}$ & & & .43 & \\
\hline Facebook is dangerous & & & & .47 \\
\hline Facebook friends are not real friends & & & & .44 \\
\hline $\begin{array}{l}\text { Facebook is a place where you can be } \\
\text { yourself }\end{array}$ & & & & -.42 \\
\hline \multicolumn{5}{|l|}{ Note. Loadings below .30 are omitted. } \\
\hline Correlations among factors & 1 & 2 & 3 & 4 \\
\hline 1 Worry about Self-Image & & & & \\
\hline 2 Worry about Privacy & -.06 & & & \\
\hline 3 Resource for Social Relations & $.23 * *$ & -.06 & & \\
\hline 4 Dangerous Place & -.01 & .08 & .03 & \\
\hline
\end{tabular}


Table 3 Hierarchical regression analysis on modality of Facebook's use Social Interaction

\begin{tabular}{lccc}
\hline Predictors & Step 1 & Step 2 & Step 3 \\
\hline Socio-demographics characteristics and actual social relations & & & \\
$\quad$ Gender (1= Female) & $.12^{*}$ & $.15^{*}$ & $.12^{*}$ \\
Age & $.14^{*}$ & $.14^{*}$ & .08 \\
Number of friends & $.16^{* *}$ & $.13^{*}$ & $.14^{*}$ \\
$\quad$ Romantic relationship (1= Engaged) & -.05 & -.08 & -.07 \\
\hline Well-being & & & \\
$\quad$ Self-esteem & & $.18^{* *}$ & $.18^{* *}$ \\
$\quad$ Satisfaction with life & & & -.03 \\
\hline Attitude towards Facebook & & & .01 \\
$\quad$ Worry about Self Image & & & $.22^{* *}$ \\
$\quad$ Worry about Privacy & & & $.23^{* *}$ \\
$\quad$ Resource for Social Relations & .04 & .06 & .23 \\
$\quad$ Dangerous Place & & &
\end{tabular}

The modality of use called Simulation (see Table 4) was negatively influenced by the wellbeing variables: self-esteem and satisfaction with life. However, three attitudes towards FB had positive effects on this dependent variable: Worry about self-image, Resource for social relations, and Dangerous place.

Finally, we regressed the modality of use Search for Relations (see Table 5). Seemingly, there were just two significant predictors. It was surprising that the attitude considering FB a Resource for social relations had no effect on the Search for social relations. We noted that gender, romantic relationship, and satisfaction with life effects disappeared entering the attitudes towards FB. These variables are related, more females $(63 \%)$ than males $(47 \%)$ were engaged in ro- mantic relationships $\left(\chi^{2}(1)=9.61, p<.01\right)$ and those participants engaged had higher scores on satisfaction with life $(t=-4.74, p<$ $.01)$. We suspected a moderation effect on Resource for social relations attitude that we tested in Step 4 of the analysis. Actually, there was a moderation effect of romantic relationship on Resource for social relations. We tested the moderation effects of gender and satisfaction with life too. They were not significant. In the final model there were three significant predictors of the modality of use Search for Relations. Worry about the privacy had a negative effect, whereas Worry about self-image and Resource for social relations had a positive effect, the last one was moderated by romantic relationship, that means that this effect exists only for the singles. 
Table 4 Hierarchical regression analysis on modality of Facebook's use Simulation

\begin{tabular}{lrrc}
\hline Predictors & Step 1 & Step 2 & Step 3 \\
\hline Socio-demographics characteristics and actual social relations & & & \\
$\quad$ Gender (1= Female) & .05 & .01 & .06 \\
Age & .07 & .04 & .02 \\
Number of friends & .02 & .07 & .06 \\
$\quad$ Romantic relationship (1= Engaged) & -.08 & .01 & .02 \\
\hline Well-being & & $-.20^{* *}$ & $-.17^{* *}$ \\
$\quad$ Self-esteem & & $-.15^{*}$ & $-.13^{*}$ \\
$\quad$ Satisfaction with life & & & \\
\hline Attitude towards Facebook & & $.37^{* *}$ \\
$\quad$ Worry about Self Image & & & -.05 \\
$\quad$ Worry about Privacy & & & $.11^{*}$ \\
$\quad$ Resource for Social Relations & .01 & .08 & .27 \\
$\quad$ Dangerous Place & & &
\end{tabular}

Table 5 Hierarchical regression analysis on modality of Facebook's use Search for Relations

\begin{tabular}{|c|c|c|c|c|}
\hline Predictors & Step 1 & Step 2 & Step 3 & Step 4 \\
\hline \multicolumn{5}{|l|}{$\begin{array}{l}\text { Socio-demographics characteristics and actual } \\
\text { social relations }\end{array}$} \\
\hline Gender (1= Female $)$ & $-.17 * *$ & $-.18 * *$ & -.06 & -.04 \\
\hline Age & .05 & .03 & -.04 & -.04 \\
\hline Number of friends & -.08 & -.07 & -.02 & -.02 \\
\hline Romantic relationship (1= Engaged) & $-.17 * *$ & $-.13 *$ & -.01 & -.01 \\
\hline \multicolumn{5}{|l|}{ Well-being } \\
\hline Self-esteem & & .05 & .09 & .09 \\
\hline Satisfaction with life & & $-.17 *$ & -.07 & -.07 \\
\hline \multicolumn{5}{|l|}{ Attitude towards Facebook } \\
\hline Worry about Self Image & & & $.17 * *$ & $.16^{* *}$ \\
\hline Worry about Privacy & & & $-.57 * *$ & $-.56 * *$ \\
\hline Resource for Social Relations & & & .05 & $.17^{* *}$ \\
\hline Dangerous Place & & & .01 & .02 \\
\hline \multicolumn{5}{|l|}{ Moderation effect } \\
\hline $\begin{array}{l}\text { Resource for Social Relations X Romantic } \\
\text { relationship }\end{array}$ & & & & $-.15^{*}$ \\
\hline a $\quad \mathrm{R}^{2}$ (corrected) & .06 & .07 & .38 & .39 \\
\hline
\end{tabular}




\section{Discussion}

The present study aimed to investigate the different ways young people use FB and the predictors of them. The factor analysis allowed to identify three main modalities of using FB. The first one (Social interaction) is the use for managing relations and for selfexpression, following the interpretation of some scholars, it is the one fulfilling social grooming needs (Gosling, 2009; Tufekci, 2008). The second modality is a potentially negative way to use social medium: the Simulation of a different self-image from reality based on the worry about what others think. The third one is the Search for relations, as literature pointed out many people use FB to meet new people (Sheldon, 2008; Urista, Dong, \& Day, 2009). Concerning opinions about FB, the factor analysis suggested four main attitudes, one positive, one negative, and two ambivalent. The positive one was called Resource for social relations; it is the belief that the social medium is a useful tool for improving social relations. On the contrary, the negative one depicts FB as dangerous and misleading (Dangerous place). The other two factors concern different worries, about self-image and privacy. Ledbetter (2009) identified five different attitudes towards online communication just partially similar to our factors. We should note that we investigated the attitude towards a specific medium (FB) whereas Ledbetter towards all the forms of online communication (i.e., some items ask the opinion about e-mail). Furthermore, in a subsequent study concerning FB use, Ledbetter and colleagues (2011) used just two of the dimensions identified in the previous study (Self-Disclosure and Social Connection) and both influenced FB use.
These dimensions are similar to our factors Worry about self-image and Resource for social relations that in the present research influenced all the modalities of using FB.

The hierarchical regression analyses allowed us to investigate the influences of the different predictors on the three main modalities of using FB. As expected, the actual social relations (number of friends) influenced the use of FB for Social interaction, supporting the interpretation that for young people this social medium may be an instrument to keep in touch with friends (Bosch, 2009; Ellison, Steinfield, \& Lampe, 2007; Lewis \& West, 2009; Pempek, Yermolayeva, $\&$ Calvert, 2009; Sheldon, 2008). The larger one's social network the more frequent the use of FB for managing it. That use is increased by self-esteem too. This result is in line with some literature (Ellison, Steinfield, \& Lampe, 2007; Gangadharbatla, 2008; Valenzuela, Park, \& Kee, 2009), people with a positive self-evaluation interact more online with their friends. The Social interaction modality of use was also influenced by three out of four attitudes towards FB. The positive and the negative ones (Resource for social relations and Dangerous place) consistently increased and decreased this kind of use. Also, the belief that it is important to take care of one's appearance online (Worry about self-image) influenced positively the frequency of Social interaction on FB.

Concerning the second modality of FB use, low self-esteem and low satisfaction with life increased the Simulation use. This data supports the hypothesized compensatory use of FB for people with poor wellbeing (Lee, Moore, Park, \& Park, 2012). It is possible that they try to compensate for the deficiency in self-esteem and satisfaction with life by simulating online a different reality. The Simula- 
tion modality of FB use is influenced by the same attitudes towards the social medium influencing the first factor (Social interaction) but in different ways. The most influencing predictor is Worry about image, the more people think that it is important to take care of the online image the more they simulate. The belief that FB is a Resource for social relation also had a positive influence, indicating that for participants the simulation behavior seems to be consistent with the aim of expanding the social network expected by the social compensatory hypothesis. That modality of use is influenced positively also by the negative attitude Dangerous place. This result suggests that Simulation may also be a defensive strategy for people not trusting in the medium but socially pressed to use it.

The use of the social medium for Searching relations was influenced positively by the Worry about self-image and negatively by Worry about privacy. Contrary to what was expected, the number of friends did not influence this modality of use. People with poor social network do not use FB to enlarge it. For young people the Search for relations use seems to be related to looking for sentimental partner rather than friends, as suggested by the moderation effect of romantic relationship on Resource for social relations attitude. People believing that FB is a Resource for social relations, when single, increase the frequency of behavior of searching for relations by means of the social medium.

Getting back to the starting assumptions, the first one was partially confirmed. As expected, the number of friends increased the FB use for managing social relations (Sheldon, 2008), whereas the relation between poor social networks and searching for relations on FB was not confirmed. People with scarce social networks do not use FB looking for new friends more than other people and not being involved in a romantic relationship has just a moderating effect on the influence of the attitude on the actual behavior.

The relations among wellbeing and use of FB confirmed the assumptions: self-esteem increases the use of FB for managing relations and for social grooming (Ellison, Steinfield, \& Lampe, 2007; Gangadharbatla, 2008; Valenzuela, Park, \& Kee, 2009), whereas low indexes of wellbeing increase the compensatory use of FB.

Finally, as expected, the various opinions about FB lead to different ways of using the social medium (Stephens \& Sætre, 2004). Concerning socio-demographic characteristics, females use FB more than males for Social interaction, whereas age does not influence the use of FB. Nevertheless, we suggest caution interpreting this last result because of the high homogeneity of the sample (Age $S D=2.38$ years).

We chose the hierarchical regression as the method of analysis because it allowed for reaching the aims of the study with a simple presentation of the results. Nevertheless, this analysis may not provide a comprehensive view of the relationship between multiple variables. A more comprehensive analysis of mutual relationships as well as prediction of Facebook use is indicated for further in-depth studies.

The present study has some limitations that should be the starting points for further research studies. First, the face-to-face social relations have been investigated indirectly (subjective perceptions). To make stronger interpretations further research should use direct indicators of the charac- 
teristics of the participants' social networks. In addition, the number of friends and the existence of a romantic relationship do not indicate the respondent's perceptions of the quality and sufficiency of the social network. For these reasons, the results concerning the actual social relationships should be interpreted with some caution. Second, wellbeing is a complex concept involving psychological and social dimensions. Future research should include more dimensions of wellbeing than the two used in our study, for example, perceived social support is an important component of quality of life and wellbeing (Heller, Watson, \& Ilies, 2006; Tartaglia, 2013). Third, the present study focused on young adults who have been the larger group of users of the new technologies and the social media. However, the situation is changing (Wilson, Gosling, \& Graham, 2012), so other age groups should be investigated in future research. Finally, the cross-sectional design of the study does not exclude the possibility that the studied relations are bidirectional, and that other variables could have intervened as moderators or mediators.

To sum up, the present study pointed out once more that people use FB in different ways and on the grounds of different beliefs. The three main modalities here identified are predicted by different variables. Concerning wellbeing, some scholars hypothesized a positive effect of using FB in terms of increasing social capital (Ellison, Steinfield, \& Lampe, 2007), however, we could not verify such a specific assumption and our data suggest being cautious. The strongest influence of wellbeing on FB use we found to be negative one on the Simulation behavior; people with poor wellbeing tend to simulate on FB. This fact should be taken into consideration when using FB for educational or social intervention purposes. Beside commercial uses, the social media can be useful for social intervention connecting people with similar problems (i.e., residents of a neighborhood, persons with the same pathology, persons with substance abuse problems). The social media may be useful for sharing information and receiving support but they imply some risks too. For the majority of the population the use of this social medium may be neither positive nor negative, but for problematic persons it may strengthen harmful modality to cope with adversities, like the construction of a false self. When treating people with problematic wellbeing traditional ways and cautious use of the social media might be a better approach.

Received August 22, 2014

\section{References}

Bauman, Z. (2000). Liquid Modernity. Cambridge: Polity press.

Bosch, T. E. (2009). Using online social networking for teaching and learning: Facebook use at the University of Cape Town. Communicatio: South African Journal for Communication Theory and Research, 35(2), 185-200.

Burke, M., Marlow, C., \& Lento, T. (2010). Social network activity and social well-being. Postgraduate Medical Journal, 85, 455-459.

Censis, UCSI (2013). Undicesimo Rapporto sulla comunicazione. L'evoluzione digitale della specie. [Eleventh report on communication. The digital evolution of the species] Milano: Franco Angeli.

Diener, E., Emmons, R. A., Larsen, R. J., Griffin, S. (1985). The Satisfaction with Life Scale. Journal of Personality Assessment, 49, 71-75.

Ellison, N. B., Steinfield, C., \& Lampe, C. (2007). The benefits of Facebook "Friends:" Social capital and college students' use of online social network sites. Journal of Computer-Mediated Communication, 12(4), 1143-1168.

Gangadharbatla, H. (2008). Facebook me: Collective self-esteem, need to belong, and internet self-efficacy as predictors of the iGeneration's 
attitudes toward social networking sites. Journal of Interactive Advertising, 8(2), 5-15.

Griffiths, M. D. (2013). Social networking addiction: Emerging themes and issues. Journal of Addiction Research \& Therapy, 4, e118. doi: 10.4172/2155-6105.1000e118

Heller, D., Watson, D., \& Ilies, R. (2006). The dynamic process of life satisfaction. Journal of Personality, 74(5), 1421-1450.

Hew, K. (2011). Students' and teachers' use of Facebook. Computers in Human Behavior, 27, 662-676.

Holzner, S. (2009). Facebook marketing: Leverage social media to grow your business. Albany, NY: SUNY press.

Kaplan, A. M., \& Haenlein, M. (2010). Users of the world, unite! The challenges and opportunities of Social Media. Business Horizons, 53(1), 59-68.

Kujath, C. L. (2011). Facebook and MySpace: Complement or substitute for face-to-face interaction? Cyberpsychology, Behavior, and Social Networking, 14(1-2), 74-78.

LaRose, R., Kim, J. \& Peng, W. (2010). Social networking: Addictive, compulsive, problematic, or just another media habit? In Z. Papacharissi (Ed.), A networked self: Identity, community, and culture on social network sites. New York, NY: Taylor \& Francis.

Ledbetter, A. M. (2009). Measuring online communication attitude: Instrument development and validation. Communication Monographs, 76 , 463-486.

Ledbetter, A. M., Mazer, J. P., DeGroot, J. M., Meyer, K. R., Mao, Y., \& Swafford, B. (2011). Attitudes toward online social connection and self-disclosure as predictors of Facebook communication and relational closeness. Communication Research, 38(1), 27-53.

Lee, J. E. R., Moore, D. C., Park, E. A., \& Park, S. G. (2012). Who wants to be "friend-rich"? Social compensatory friending on Facebook and the moderating role of public self-consciousness. Computers in Human Behavior, 28(3), 1036 1043.

Lewis, J., \& West, A. (2009). 'Friending': Londonbased undergraduates' experience of Facebook. New Media \& Society, 11(7), 1209-1229.

Li, C. (2014). A tale of two social networking sites: How the use of Facebook and Renren influences Chinese consumers' attitudes toward product packages with different cultural symbols. Computers in Human Behavior, 32, 162-170.
Manago, A. M., Taylor, T., Greenfield, P. M. (2012). Me and my 400 friends: The anatomy of college students' Facebook networks, their communication patterns, and well-being. Developmental Psychology, 48(2), 369-380.

Mehdizadeh, S. (2010). Self-presentation 2.0: Narcissism and self-esteem on Facebook. Cyberpsychology, Behavior, and Social Networking, 13(4), 357-364.

Pempek, T. A., Yermolayeva, Y. A., \& Calvert, S. (2009). College students' social networking experiences on Facebook. Journal of Applied Developmental Psychology, 30(3), 227-238.

Prescott, J. (2014). Teaching style and attitudes towards Facebook as an educational tool. Active Learning in Higher Education, 15(2), 117-128.

Prezza, M., Trombaccia, F. R., \& Armento, L. (1997). La scala dell'autostima di Rosenberg: Traduzione e validazione italiana [The Rosenberg self-esteem scale: Italian translation and validation. Bollettino di Psicologia Applicata, 223, 3544

Ryan, T., Chester, A., Reece, J., \& Xenos, S. (2014). The uses and abuses of Facebook: A review of Facebook addiction. Journal of Behavioral Addictions, 3(3), 133-148.

Sagioglou, C., \& Greitemeyer, T. (2014). Facebook's emotional consequences: Why Facebook causes a decrease in mood and why people still use it. Computers in Human Behavior, 35, 359-363.

Sheldon, P. (2008). Student favourite: Facebook and motives for its use. Southwestern Mass Communication Journal, 23(2), 39-53.

Skues, J. L., Williams, B., \& Wise, L. (2012). The effects of personality traits, self-esteem, loneliness, and narcissism on Facebook use among university students. Computers in Human Behavior, 28(6), 2414-2419.

Stephens, K. K., \& Sætre, A. S. (2004). Media choice and ICT use. In L. D. Browning, A. S. Sætre, K. K. Stephens, \& J. Sørnes (Eds.), Information and communication technology in action: Linking theory and narratives of practice (pp. 27-35). Oslo, Sweden: Abstrakt Forlag.

Tartaglia, S. (2013). Different predictors of quality of life in urban environment. Social Indicators Research, 113(3), 1045-1053.

Urista, M. A., Dong, Q., \& Day, K. D. (2009). Explaining why young adults use MySpace and Facebook through uses and gratifications theory. Human Communication, 12(2), 215-229.

Valenzuela, S., Park, N., \& Kee, K. F. (2009). Is there social capital in a social network site?: 
Facebook use and college students' life satisfaction, trust, and participation. Journal of Computer-Mediated Communication, 14(4), 875901.

Wilson, R. E., Gosling, S. D., \& Graham, L. T. (2012). A review of Facebook research in the social sciences. Perspectives on Psychological Science, 7(3), 203-220.
Wise, K., Alhabash, S., \& Park, H. (2010). Emotional responses during social information seeking on Facebook. Cyberpsychology, Behavior, and Social Networking, 13, 555-562.

Zhao, S., Grasmuck, S., \& Martin, J. (2008). Identity construction on Facebook: Digital empowerment in anchored relationships. Computers in Human Behavior, 24(5), 1816-1836. 